\title{
Evaluation of fetal fibronectin rapid bedside test as a predictor of preterm labour: a prospective study
}

\author{
Kusum Dogra*, Meenakshi Tanwar
}

Department of Obstetrics and Gynecology, Shri Guru Ram Rai Institute of Medical Health and Sciences, SMIH, Patel Nagar, Dehradun, Uttarakhand, India

Received: 21 July 2019

Revised: 15 August 2019

Accepted: 19 August 2019

*Correspondence:

Dr. Kusum Dogra,

E-mail: drkusumdogra@gmail.com

Copyright: (c) the author(s), publisher and licensee Medip Academy. This is an open-access article distributed under the terms of the Creative Commons Attribution Non-Commercial License, which permits unrestricted non-commercial use, distribution, and reproduction in any medium, provided the original work is properly cited.

\begin{abstract}
Background: Preterm birth defined as birth before 37 weeks of gestation is a significant public health issue. Identification of patients at risk of preterm labour while ruling out those who are not is a fundamental but challenging goal for clinicians. This study was done to evaluate bed side dipstick test for detecting fetal fibronectin in cervicovaginal secretions as a predictor of preterm delivery in symptomatic and asymptomatic high risk group.

Methods: This was a hospital based prospective, double blinded study. We enrolled 100 pregnant women presenting with or without symptoms of preterm delivery, between 20 and 35 weeks of gestation. A rapid bed side dipstick test was performed to detect FFN in cervico-vaginal secretions of all enrolled women (symptomatic and asymptomatic high risk women) and results were evaluated for prediction of preterm labour. Qualitative data were analyzed by using Chi-square and Fisher's exact test and quantitative data were analyzed by using unpaired Student's t test and MannWhitney test. P value $<0.05$ was considered significant.

Results: In symptomatic group sensitivity, specificity, PPV and NPV of FFN test in predicting delivery within 48 hours, 7days 14days and preterm delivery was 100\%, 63.2\%, 46.2\%, 100\%; 100\%, 72.7\%, 65.4\%, 100\%; 100\%, $75 \%, 69.2 \%, 100 \% ; 80 \%, 76 \%, 76.9 \%, 79.2 \%$ respectively. In asymptomatic high risk group, sensitivity, specificity, PPV and NPV of FFN test in predicting preterm delivery (<37weeks) was $0 \%, 87.5 \%, 0 \%, 77.8 \%$.

Conclusions: The high negative predictive value may be of value in avoiding unnecessary interventions with potentially hazardous medications and identifying symptomatic women who are not in true labour and also allaying anxiety of asymptomatic high risk women.
\end{abstract}

Keywords: Fetal fibronectin test, Preterm delivery, Positive predictive value, Negative predictive value, Quick check test

\section{INTRODUCTION}

Preterm birth defined as birth before 37 weeks of gestation is a significant public health issue. Despite advances in obstetrics care, approx 1 in 10 infants is born preterm. It accounts for $75-85 \%$ of perinatal mortality, with mortality directly proportional to decreasing gestational age. ${ }^{1}$ Prematurity is also a major source of morbidity with overwhelming long term disability and economic consequences. ${ }^{2}$ Preterm birth is associated with wide array of serious health issues, neuro-developmental disability, chronic respiratory diseases, gastrointestinal complications, central nervous system problems, long term cognitive, motor and behavioral delay. ${ }^{3}$ Spontaneous 
preterm labour with intact membranes is responsible for approximately $30 \%$ of preterm birth and premature labour is the most common cause of maternal antenatal hospital admission. ${ }^{4}$

Accurate diagnosis of preterm labour is not so simple and many false positive diagnoses have been made using parameters like uterine contractions and effacement. The choriodecidua complex produces many proteins including interleukin-1, IL6, IL8, and TNF a. All of these proteins have been evaluated as biochemical markers of threatened preterm delivery. In recent times new markers like FFN and phIGFBP-1 have been employed to arrive at diagnosis of preterm labour. ${ }^{5,6-8}$

FFN is glycoprotein found in amniotic fluid, placental tissue and deciduae basalis. Although its specific function remains uncertain, it is thought to play a role in implantation and placental uterine attachment. It can be detected in cervico-vaginal secretion of women in early pregnancy, but in a normal pregnancy it becomes no longer detectable after 24 weeks of gestation. However, as the labour approaches it re appear in cervico-vaginal secretions due to disruption of chorionic decidual interface. The presence of positive cervical FFN test after 20 weeks of gestation represents an increase risk of preterm delivery and its absence ensures that women is not at risk. ${ }^{9-11}$

Therefore presence of FFN in cervico-vaginal fluid after 20 weeks is marker for preterm labour. Initial studies establishing the presence of fetal fibronectin in cervicovaginal secretions involved extensive laboratory analysis that delayed the availability of results. An enzyme linked immunosorbent assay containing FDC-6 monoclonal antibody has been developed that can be used at bedside, potentially making this test as a stronger clinical tool. Since there is paucity of Indian studies to address this issue, thus present study was designed.

In present study FFN rapid bed side dipstick test is evaluated for predicting preterm labour in symptomatic and asymptomatic high risk group.

\section{METHODS}

A hospital based prospective, double blinded observational study was conducted at Vardhman Mahavir Medical College and Safdarjung hospital, New Delhi. Total 100 patients were recruited, test was conducted and patients were followed till delivery in present study from April 2011 to April 2013. Fifty pregnant women with gestation age between 20-35 weeks, attending gynecology emergency with symptoms of preterm labour e g pelvic pressure, low abdominal cramps, uterine contraction, discharge per vaginum were included in group A (Symptomatic women). Group B (Asymptomatic high risk) includes another fifty pregnant women with gestational age between 20-35 weeks attending antenatal outpatient department without any symptoms of preterm labour but having high-risk factor for preterm labour like women with multiple pregnancies or women with history of previous preterm birth or second trimester abortion. Women who presented with premature rupture of membrane, cervical dilatation more than $3 \mathrm{~cm}$, excessive bleeding per vaginum and other maternal and fetal indication requiring early termination of pregnancy like intrauterine fetal growth restriction, congenital fetal anomalies and severe preeclampsia were excluded from the study.

After informed consent, patients were enrolled in this study. Gestational age was calculated from last menstrual date or first trimester ultrasound. Detailed history, general physical examination and per abdominal examination were done. Rapid bedside dipstick test using Quick Check FFN were performed to detect Fetal Fibronectin in cervico-vaginal secretions before any internal examination During per speculum examination, sterile applicator tip was rotated in posterior fornix of vagina for 10 seconds to absorb cervico-vaginal secretions. The applicator was removed and inserted into test tube with buffer, mixed vigorously for 10-15 seconds and then discarded. Test strip was then inserted into buffer for $10 \mathrm{~min}$. Results was read, two lines i e one test and one control line as positive, one line that is one control line as negative and absence of distinct control line as invalid test. Detailed pelvic examination was done to note cervical dilatation and effacement. Cervical length was assessed by transvaginal sonography with $5 \mathrm{MHz}$ vaginal probe transducer. Cervical length less than 25 $\mathrm{mm}$ was used as cutoff criteria for predicting preterm delivery which represents 10th percentile of cervical length measurements.

\section{Statistical analysis}

Both subjects and treating obstetrician were blinded to the results of test and treatment was given as per hospital protocol. All the patients in symptomatic group were admitted in hospital and were administered corticosteroids and tocolytic medications. Route of delivery were individualized and caesarean section were performed according to obstetrical indication. All patients were followed till delivery. Test results were noted and analyzed. Qualitative data were analyzed by using Chisquare test and Fisher's exact tests whereas quantitative data were analyzed by using unpaired Student $t$ test and Mann Witney's test. Multiple logistic regressions were performed to assess the independent contributions of different variables in prediction of preterm delivery. $\mathrm{P}$ value $<0.05$ was considered significant. SPSS statistically software version 12.0 was used for data analysis.

\section{RESULTS}

Clinical characteristics of population are outlined in Table 1. In symptomatic group mean age of patients was $23.38 \pm 3.77$ years, mean gestation age 29.9143 \pm 3.688 weeks, mean BMI was $25.6640 \pm 7.441 \mathrm{~kg} / \mathrm{m}^{2}$, mean 
cervical length was $36.554 \pm 7.28 \mathrm{~mm}$. Whereas in Asymptomatic high risk group, mean age of patients was $24.12 \pm 2.94$ years, mean gestational age was $29.44 \pm 2.92$ weeks, mean BMI was $25.39 \pm 6.34 \mathrm{~kg} / \mathrm{m}^{2}$ and mean cervical length was37.230 $\pm 4.4 \mathrm{~mm}$ (Table 1).

Table 1: Obstetrics variables.

\begin{tabular}{|c|c|c|}
\hline Characteristics & $\begin{array}{l}\text { Symptomati } \\
\text { c }(n=50)\end{array}$ & $\begin{array}{l}\text { Asymptomatic } \\
\text { high risk }(\mathrm{n}=50)\end{array}$ \\
\hline \multicolumn{3}{|l|}{ 1-age } \\
\hline$<20$ Years & $7(14 \%)$ & $0(0 \%)$ \\
\hline 20-24 Years & $28(56 \%)$ & $28(56 \%)$ \\
\hline 25-29 Years & $11(22 \%)$ & $19(38 \%)$ \\
\hline$>30$ Years & $4(8 \%)$ & $3(6 \%)$ \\
\hline Mean \pm SD & $23.38 \pm 3.7$ years & $\begin{array}{l}24.12 \pm 2.94 \\
\text { years }\end{array}$ \\
\hline \multicolumn{3}{|l|}{ 2-gestational age } \\
\hline$<32$ weeks & $30(60 \%)$ & $37(74 \%)$ \\
\hline 32-34weeks & $18(36 \%)$ & $13(26 \%)$ \\
\hline >34weeks & $2(4 \%)$ & $0(0 \%)$ \\
\hline Mean \pm SD & $29.9 \pm 3.6$ weeks & $\begin{array}{l}29.44 \pm 2.92 \\
\text { weeks }\end{array}$ \\
\hline \multicolumn{3}{|l|}{ 3-parity } \\
\hline G 1 & $22(44 \%)$ & $0(0 \%)$ \\
\hline G2 & $19(38 \%)$ & $29(58 \%)$ \\
\hline G3 & $4(8 \%)$ & $16(32 \%)$ \\
\hline G4 & $5(10 \%)$ & $4(8 \%)$ \\
\hline$>$ G5 & $0(0 \%)$ & $1(2 \%)$ \\
\hline \multicolumn{3}{|l|}{ 3-BMI kg/m² } \\
\hline$<19.8$ & $13(26 \%)$ & $10(20 \%)$ \\
\hline $19.8-26$ & $18(36 \%)$ & $20(40 \%)$ \\
\hline $26.1-29$ & $4(8 \%)$ & $3(6 \%)$ \\
\hline$>=29$ & $15(30 \%)$ & $17(34 \%)$ \\
\hline Mean \pm SD & $25.6 \pm 7.4 \mathrm{~kg} / \mathrm{m}^{2}$ & $25.39 \pm 6.34 \mathrm{~kg} / \mathrm{m}^{2}$ \\
\hline \multicolumn{3}{|c|}{ 4-cervical length } \\
\hline$<25 \mathrm{~mm}$ & $6(12 \%)$ & $2(4 \%)$ \\
\hline $26-35 \mathrm{~mm}$ & $10(20 \%)$ & $12(24 \%)$ \\
\hline$>34 \mathrm{~mm}$ & $34(68 \%)$ & $36(72 \%)$ \\
\hline Mean \pm SD & $36.55 \pm 4.43 \mathrm{~mm}$ & $37.230 \pm 4.9 \mathrm{~mm}$ \\
\hline \multicolumn{3}{|c|}{ 5-high-risk factors } \\
\hline $\begin{array}{l}\text { Previous } \\
\text { preterm birth }\end{array}$ & nil & $15(30 \%)$ \\
\hline $\begin{array}{l}\text { Previous second } \\
\text { trimester } \\
\text { abotion }\end{array}$ & nil & $35(70 \%)$ \\
\hline $\begin{array}{l}\text { Multiple } \\
\text { pregnancy }\end{array}$ & nil & $0(0 \%)$ \\
\hline
\end{tabular}

Logistic regression is a type of regression analysis used for predicting outcome of categorical criterion variable based on one or more predictor variable. In Symptomatic group, by using multiple logistic regression analysis controlling for different risk factors for preterm delivery, positive FFN test and cervical length $=25 \mathrm{~mm}$ remained independent risk factor for preterm delivery (Table 2).
Table 2: Risk estimation in symptomatic group.

\begin{tabular}{|lll|}
\hline Variables & Odd ratio & $95 \%$ CI \\
\hline Age $<24 />24$ years & 0.56 & $.16 / 1.9$ \\
\hline Gestational age & 0.4 & $.12 / 1.3$ \\
\hline Multi/nullipara & 0.72 & $.23 / 2.2$ \\
\hline Veg/nonveg & 0.84 & $.26 / 2.6$ \\
\hline Bmi $<19.8 />19.8$ & 0.81 & $.22 / 2.8$ \\
\hline Cervical length $<25 />25 m m$ & 6 & $.64 / 55.6$ \\
\hline Previous h/o preterm birth & 0.4 & $.1 / 1.5$ \\
\hline FFN positive/negative & 4.33 & $1.2 / 15.2$ \\
\hline
\end{tabular}

BMI: Body mass index; FFN: Fetal fibronectin test

Table 3: Evaluation of FFN test in predictiing delivery within 14 days in symptomatic and asymptomatic high risk group.

\begin{tabular}{|c|c|c|}
\hline \multicolumn{3}{|c|}{ Symptomatic group } \\
\hline $\begin{array}{l}\text { Test } \\
\text { results }\end{array}$ & $\begin{array}{l}\text { Delivery <=14 days } \\
\text { from test }\end{array}$ & $\begin{array}{l}\text { Delivery >14 days } \\
\text { from test }\end{array}$ \\
\hline $\begin{array}{l}\mathrm{FFN}+ \\
(\mathrm{n}=26)\end{array}$ & $18(69.2 \%)$ & $8(30.7 \%)$ \\
\hline $\begin{array}{l}\text { FFN_(n= } \\
24)\end{array}$ & $0(0 \%)$ & $24(100 \%)$ \\
\hline \multicolumn{3}{|c|}{ Asymptomatic high risk } \\
\hline $\begin{array}{l}\text { Test } \\
\text { results }\end{array}$ & $\begin{array}{l}\text { Delivery <=14 days } \\
\text { from test }\end{array}$ & $\begin{array}{l}\text { Delivery >14 days } \\
\text { from test }\end{array}$ \\
\hline $\begin{array}{l}\mathrm{FFN+} \\
(\mathrm{n}=1)\end{array}$ & 0 & $1(100 \%)$ \\
\hline $\begin{array}{l}\text { FFN } \\
(n=49)\end{array}$ & 0 & $49(100 \%)$ \\
\hline
\end{tabular}

FFN+: fetal fibronectin positive test; FFN_: fetal fibronectin negative test

Table 4: Evaluation of FFN test in predicting delivery within 48 hours, within 7 days and within 14 days in symptomatic group.

\begin{tabular}{|llll|}
\hline & $\begin{array}{l}\text { Delivery } \\
\text { within } 48 \\
\text { hours }\end{array}$ & $\begin{array}{l}\text { Delivery } \\
\text { within } 7 \\
\text { days }\end{array}$ & $\begin{array}{l}\text { Delivery } \\
\text { within 14 } \\
\text { days }\end{array}$ \\
\hline $\begin{array}{l}\text { FFN }+ \\
(\mathrm{n}=26)\end{array}$ & $12(46.2 \%)$ & $17(65.4 \%)$ & $18(69.23 \%)$ \\
\hline
\end{tabular}

FFN+: Fetal fibronectin positive test

In symptomatic group, out of 50 patients who presented with preterm labour 52\% $(n=26)$ tested positive while $48 \%(n=24)$ were tested negative for bed side dipstick test for FFN. Eighteen out of 26 (69.2\%) who were tested positive with FFN test delivered within 14 days, thus making PPV 69.2\% while none of patients who were tested negative delivered within 14 days thus $\mathrm{NPV}=100 \%$, which is statistically significant $p$ value $=0.000$ (Table 3). Whereas in asymptomatic high risk group only one out of fifty patients was tested positive for FFN dipstick test and all the fifty patients delivered $>14$ days after test. Since time from test to delivery within 14 days remains constant so no statistics could be computed (Table 3 ). 
In symptomatic group, 12 out of 26 patients with positive FFN $46.2 \% \quad(n=12 / 26)$ delivered within 48hrs, $65.4 \%$ patients $(n=17 / 26)$ delivered within 7 days while $69.23 \%$ patients $(n=18 / 26)$ delivered within 14 days (Table 4). Sensitivity, specificity, PPV, NPV of FFN in symptomatic group for predicting risk of delivery within 48 hours, 7 days, 14 days were calculated (Table 5). In symptomatic group sensitivity, specificity, PPV and NPV of FFN test in predicting delivery within 48 hours, 7 days, 14 days was $100 \%, 63.2 \%, 46.2 \%, 100 \% ; 100 \%$, $72.7 \%, 65.4 \%, 100 \% ; 100 \%, 75 \%, 69.2 \%, 100 \%$ respectively (Table 5).

Table 5: Efficacy of FFN Test in predicting delivery within 48 hours, within 7 days and within 14 days in symptomatic group.

\begin{tabular}{|llll|}
\hline Statistics & $\begin{array}{l}\text { Delivery } \\
<=48 \text { hours }\end{array}$ & $\begin{array}{l}\text { Delivery } \\
<=7 \text { days }\end{array}$ & $\begin{array}{l}\text { Delivery } \\
<=14 \text { days }\end{array}$ \\
\hline Sensitivity & $100 \%$ & $100 \%$ & $100 \%$ \\
\hline Specificity & $63.20 \%$ & $72.70 \%$ & $75 \%$ \\
\hline PPV & $46.20 \%$ & $65.40 \%$ & $65.40 \%$ \\
\hline NPV & $100 \%$ & $100 \%$ & $100 \%$ \\
\hline p value & 0 & 0 & 0 \\
\hline Positive LR & 19.218 & 30.56 & 33.242 \\
\hline
\end{tabular}

PPV: Positive predictive value; NPV: Negative predictive value; LR: Likelihood ratio; FFN: Fetal Fibronectin test.

Table 6: Evaluation of FFN test in predicting preterm delivery in symptomatic and asymptomatic high-risk group.

\begin{tabular}{|c|c|c|}
\hline \multicolumn{3}{|c|}{ Symptomatic group } \\
\hline Test results & $\begin{array}{l}\text { Delivery } \\
<=37 \text { weeks }\end{array}$ & $\begin{array}{l}\text { Delivery >37 } \\
\text { weeks }\end{array}$ \\
\hline $\mathrm{FFN}+(\mathrm{n}=26)$ & $20(76.9 \%)$ & $6(23 \%)$ \\
\hline FFN_(n=24) & $5(20.8 \%)$ & $19(79.2 \%)$ \\
\hline \multicolumn{3}{|c|}{ Asymptomatic high-risk } \\
\hline Test results & $\begin{array}{l}\text { Delivery <=37 } \\
\text { weeks }\end{array}$ & $\begin{array}{l}\text { Delivery >37 } \\
\text { weeks }\end{array}$ \\
\hline $\mathrm{FFN}+(\mathrm{n}=1)$ & 0 & $1(100 \%)$ \\
\hline FFN_(n=49) & $10(20.4 \%)$ & $39(79.6 \%)$ \\
\hline
\end{tabular}

FFN+: Fetal fibronectin positive test; FFN_: Fetal fibronectin negative test.

In symptomatic group, $76.9 \%$ patients $(n=20 / 26)$ with FFN positive result delivered preterm and $23 \%(n=6 / 26)$ delivered at term. Out of 24 patients with FFN negative test, $5(20.8 \%)$ patients delivered preterm and $19(79.2 \%)$ delivered at term (Table 6). Whereas in asymptomatic high risk group, 10 patients $(20.4 \%)$ delivered preterm and 39 patients $(79.6 \%)$ delivered at term (Table 6). Sensitivity, specificity, PPV, NPV of FFN in predicting preterm delivery in symptomatic high risk group was $80 \%, 76 \%, 76.9 \%$ and $79.2 \%$. Whereas sensitivity, specificity, PPV, NPV of FFN in predicting preterm delivery in asymptomatic high-risk group was $0 \%$, $97.5 \%, 0 \%, 79.6 \%$. Positive likelihood ratio of FFN in predicting preterm delivery in asymptomatic high risk group was 0.451 . Though the findings were statistically insignificant (Table 7).

Table 7: Efficacy of FFN test in predicting preterm delivery $(<=37$ weeks in symptomatic versus asymptomatic high-risk group).

\begin{tabular}{|lll|}
\hline Statistics & Symptomatic & $\begin{array}{l}\text { Asymptomatic } \\
\text { high-risk }\end{array}$ \\
\hline Sensitivity & $80 \%$ & 0 \\
\hline Specificity & $76 \%$ & $97.50 \%$ \\
\hline PPV & $76.90 \%$ & $0 \%$ \\
\hline NPV & $79.20 \%$ & $79.60 \%$ \\
\hline p value & 0 & 0.614 \\
\hline Positive LR & 16.661 & 0.451 \\
\hline
\end{tabular}

PPV: Positive predictive value; NPV: Negative predictive value; LR: Likelihood ratio; FFN: Fetal Fibronectin test.

Table 8: Correlation between cervical length (CL) and FFN test in predicting preterm labour in symptomatic group.

\begin{tabular}{|lll|}
\hline Statistics & CL & CL+FN \\
\hline Sensitivity & 0.2 & 0.8 \\
\hline Specificity & 0.96 & 0.52 \\
\hline PPV & 0.833 & 0.625 \\
\hline NPV & 0.545 & 0.722 \\
\hline p value & 0.082 & 0.18 \\
\hline Positive LR & 3.275 & 5.704 \\
\hline
\end{tabular}

PPV: Positive predictive value; NPV: Negative predictive value; LR: Likelihood ratio; FFN: Fetal Fibronectin test; CL: Cervical Length.

In symptomatic group cervical length $<=25 \mathrm{~mm}$ is very specific and PPV of the test in predicting preterm delivery is very high $83.3 \%$. When cervical length findings were combined with FFN test, NPV increases though the findings are statistically insignificant (Table $8)$. Whereas in asymptomatic high-risk group cervical length $<=25 \mathrm{~mm}$ had high NPV $79.2 \%$, however when cervical length is combined with FFN test it does not increase the NPV. The findings were statistically insignificant (Table 9).

Table9: Correlation between cervical length (CL) and FFN test in predicting preterm delivery in asymptomatic high-risk group.

\begin{tabular}{|lll|}
\hline Statistics & CL & CL+FN \\
\hline Sensitivity & 0 & 0 \\
\hline Specificity & 0.95 & 0.825 \\
\hline PPV & 0 & 0 \\
\hline NPV & 0.792 & 0.767 \\
\hline p value & 0.47 & 0.154 \\
\hline Positive LR & 0.913 & 3.398 \\
\hline
\end{tabular}

PPV: Positive predictive value; NPV: Negative predictive value; LR: Likelihood ratio; FFN: Fetal Fibronectin test; CL: Cervical Length. 


\section{DISCUSSION}

Preterm birth, delivery before 37 weeks of gestation, is a major obstetric and global health problem. It is the largest direct cause of mortality in infants aged less than 5 years and associated with serious morbidity in the surviving infants. $^{12,13}$ In present study we evaluated bed side dipstick test for detecting fetal fibronectin in cervicovaginal secretions as a predictor of preterm delivery in symptomatic and Asymptomatic high risk group.

Numerous studies have demonstrated that FFN is an excellent marker of preterm delivery with NPV $>99 \%$ for predicting delivery sensitivity, specificity, PPV, NPV of FFN in predicting delivery within 7 days within 7 and 14 days in symptomatic women. Body of literature related to FFN testing is large but heterogeneous. Some studies include only symptomatic patients while other includes only asymptomatic high risk group. Some studies evaluated the use of FFN testing with other predictors like risk scoring systems, bacterial vaginosis, or cervical length and other ultrasound measures in low risk population.

Identification of patients at risk of preterm labour while ruling out those who are not is a fundamental but challenging goal for clinicians. Sensitivity, specificity, PPV, NPV of FFN in predicting delivery within 14 days and preterm delivery in symptomatic group in our study was $100 \%, 75 \%, 69.2 \%, 100 \%$ and $80 \%, 76 \%, 76.7 \%$, $78.2 \%$ respectively. The high NPV of FFN test may be of value may be of great value in avoiding unnecessary interventions with potentially hazardous medications in patients with uterine contractions and healthcare utilization by more accurately identifying symptomatic women who are not in true labor.

In asymptomatic high-risk group, FFN test was positive in only 1 patient who delivered after 14 days from test and at term. Sensitivity, specificity, PPV, NPV of FFN in predicting preterm delivery in asymptomatic high risk group in our study was $0 \%, 97.5 \%, 0 \%, 79.6 \%$.The high NPV in predicting preterm delivery in asymptomatic high risk group may be of value in not only avoiding unnecessary hospital admission but also allaying the anxiety of these patients

Our observation was similar to study conducted by Ismail Tekesin et al, who had reported sensitivity, specificity, PPV, NPV of FFN in predicting delivery within 7 days as $81.8 \%, 76.7 \%, 19.6 \%, 98.4 \%$ respectively. ${ }^{14}$ Sensitivity, specificity, PPV, NPV of FFN in predicting delivery within 14 days was reported as $87.5 \%, 79.2 \%, 30.4 \%$ and 98.4\% respectively. Peaceman AM et al, reported high negative predictive values in predicting delivery within 7 days, 14 days and at $<37$ weeks as $99.5 \%, 99.2 \%$ and $84.5 \%$ respectively. ${ }^{15}$

In recent randomized controlled trial of 97 women, Lowe et al, reported that a negative FFN test was associated with fewer and shorter ante partum admissions. ${ }^{16}$ In contrast, Grobman et al, found that FFN did not influence physician behavior or health care costs. ${ }^{17}$ The use of predictive tests for preterm labour and their influence on clinical behavior is an area that could be further examined.

Limitations with FFN testing are recognized. FFN is found in male semen, maternal serum, and can be elicited with the inflammation caused by digital examination. A patient presenting with preterm labour symptoms with the history of vaginal examination or intercourse within 24 hours is usually excluded from testing due to a higher probability of a false positive result. FFN also has the shortcoming of its expense and requires outside laboratory personnel for processing.

FFN test provide useful information when there is uncertainty about whether to transport a symptomatic women for preterm labor from primary health care to higher centre with neonatal intensive care facilities. This test when conducted in women presenting for healthcare is at high risk for imminent preterm delivery would be valuable in enabling the choice of the most appropriate interventions for prolonging gestation.

\section{CONCLUSION}

Rapid bedside dipstick test for detecting FFN in cervicovaginal secretions seems to be future milestone in ruling out delivery within 14 days thus avoiding unnecessary hospital stay and medical interventions. The high negative predictive value may be of value in avoiding unnecessary interventions with potentially hazardous medications and identifying symptomatic women who are not in true labour and also allaying anxiety of asymptomatic high risk women.

\section{Funding: No funding sources Conflict of interest: None declared \\ Ethical approval: Not required}

\section{REFERENCES}

1. Copper RL, Goldenberg RL, Creasy RK, DuBard MB, Davis RO, Entman SS, et al. A multicenter study of preterm birth and gestational age- specific neonatal mortality. Am J Obstet Gynecol. 1993;168(1Pt 1):78-84.

2. Crowley P. Prophylactic corticosteroids for preterm birth. Cochrane Pregnancy and childbirth group. Cochrane Database of Syst Rev. 2003:3.

3. Mercer BM, Goldenberg RL, Moawad AH, Meis PJ, Iams JD, Das AF, Caritis SN, et al. The preterm prediction study: effects of gestational age and cause of preterm birth on subsequent obstetric outcome. Am J Obstet Gynecol. 1999;181(5 Pt 1):1216-21.

4. Haram K, Mortensen JH, Wollen AL. Preterm delivery: an overview. Acta Obstet Gynecol Scand. 2003;82(8):687-704. 
5. Lockwood CJ, Senyei AE, Dische MR, Casal D, Shah KD, Thung SN, et al. Fetal fibronectin in cervical and vaginal secretions as a predictor of preterm delivery. N Engl J Med. 1991;325(10):66974.

6. Nageotte MP, Casal D, Senyei AE. Fetal fibronectin in patients at increased risk for premature birth. Am J Obstet Gynecol. 1994;170(1Pt1):20-5.

7. Cherouny PH, Pankuch GA, Romero R, Botti JJ, Kuhn DC, Demers LM, et al. Neutrophil attractant/activating peptide-1/interleukin-8: association with histologic chorioamnionitis, preterm delivery, and bioactive amniotic fluid leukoattractants. Am J Obstet Gynecol. 1993;169(5):1299-303.

8. Inglis SR, Jeremias J, Kuno K, Lescale K, Peeper Q, Chervenak FA, et al. Detection of tumor necrosis factor -alpha, interleukin-6, and fetal fibronectin in the lower genital tract during pregnancy: relation to outcome. Am J Obstet Gynecol. 1994;171(1): 5-10.

9. Closset E, Dufour P, Coeugnet C, Subtil D, Valat AS, Puech F. Value of fetal fibronectin research for predicting premature delivery. Gynecol Obstet Fertil. 2001;29(11):808-13.

10. Morrison JC, Allbert JR, McLaughlin BN, Whitworth NS, Roberts WE, Martin RW. Oncofetal fibronectin in patients with false labor as a predictor of preterm delivery. Am J Obstet Gynecol. 1993;168(2):538-42.

11. Goldenberg RL, Mercer BM, Meis PJ, Copper RL, Das A, McNellis D. The preterm prediction study: Fetal fibronectin testing and spontaneous preterm birth: NICHD Maternal Fetal Medicine Units Network.Obstet Gynecol. 1996;87(5 Pt 1):643-8.
12. Moore T, Hennessy EM, Myles J. Neurological and developmental outcome in extremely preterm children born in England in 1995 and 2006: the EPI Cure studies. Br Med J. 2012;345:217-24.

13. Blencowe H, Cousens S, Chou D. Born too soon: the global epidemiology of 15 million preterm births. Reprod Health. 2013;10:S2.

14. Tekesin I, Marek S, Hellmeyer L, Reitz D, Schmidt S. Assessment of rapid fetal fibronectin in predicting preterm delivery. Obstet Gynecol. 2005;105(2):2804.

15. Peaceman AM, Andrews WW, Thorp JM, Cliver SP, Lukes A, Iams JD, et al. Fetal fibronectin as a predictor of preterm birth in patients with symptoms: a multicentre trial. Am J Obstet Gynecol. 1997;177(1):13-8.

16. Lowe MP, Zimmerman B, Hansen W. Prospective randomized controlled trial of fetal fibronectin or preterm labor management in a tertiary care centre. Am J Obstet Gynecol. 2004;190(2):358-62.

17. Grobman WA, Welshman EE, Calhoun EA. Does fetal fibronectin use in the diagnosis of preterm labor affect physician behavior and health care costs? A randomized trial. Am J Obstet Gynecol. 2004;191(1):235-40.

Cite this article as: Dogra K, Tanwar M. Evaluation of fetal fibronectin rapid bedside test as a predictor of preterm labour: a prospective study. Int J Reprod Contracept Obstet Gynecol 2019;8:3447-52. 